\title{
Editorial
}

\section{Sri Lanka Journal of Sexual Health and HIV Medicine (Sri Lanka JoSHH)}

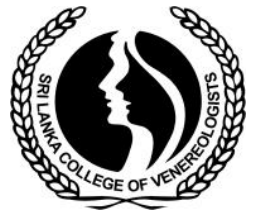

Editorial Board

\section{Editor-in-chief}

Dr Ariyaratne Manathunge MBBS, MSc, MD, FSLCV

\section{Acquisition editor}

Dr Darshani Wijayawickrama MBBS, PgDip Ven, MD

\section{Assistant editors}

Dr Nalaka Abeygunasekara MBBS, PgDip Ven, MD

Dr Ajith Karawita MBBS, PgDip Ven, MD, FSLCoSHH

\section{Editorial board members}

Dr Carukshi Arambepola MBBS (Colombo), MSc and MD (Community Medicine)

Dr Lilani Rajapakse

MBBS, MSc, MD, FSLCV

Dr. Manjula Rajapakshe MBBS, PgDip Ven, MD

\section{Secretary}

Dr Vindya Kaluarachchi MBBS, PgDip Ven, MD
Sri Lanka College of Sexual Health and HIV Medicine is proud to issue the third volume of Sri Lanka Journal of Sexual Health and HIV Medicine which is the official journal of the College. As you are aware this journal is the successor to the Sri Lanka Journal of Venereology.

Presidential address at the inaugural session of the Sri Lanka College of Sexual Health and HIV Medicine, 2017, is the leading article of this volume which is titled "Stepping in to the future". This article steps across the mile stones of the past, the present and future of the HIV epidemic.

Today HIV/AIDS has changed from a deadly disease to a condition that is compatible with normal life, provided that infected persons receive an early diagnosis and antiretroviral therapy.

Although there are research approaches, there is no cure for HIV on the horizon. Similarly, vaccine trials have not shown adequate protection against HIV.

The concepts of HIV prevention have evolved over past few decades. During the early period, the principal preventive approaches were based on attempts to change behaviours, with strengthening the social norm of safe sex and condom use.

Recent biomedical innovations are gradually replacing the behavioural model of HIV prevention to medicalization of HIV prevention: HIV testing and provision of antiretrovirals (treatment as prevention, pre and post exposure prophylaxis).

The major change in this regard is the shift from the discipline related sexual behaviour to a discipline related health behaviour; HIV testing and medication. However, medicalization of HIV prevention cannot be effective without the sustained use of some behavioural approaches.

Ariyaratne Manathunge

iD https://orcid.org/0000-0001-9514-9227

\section{Editor-in-chief}

(http://www.who.int/reproductivehealth/topics/sexual_health/i ssues/en/) 